\title{
Relationship between the quality of life of the caregiver and motor function of children with cerebral palsy
}

\author{
Chang-Kyo Yun
}

Department of Physical Therapy, Rehabilitation Clinic of Daegu University, College of Rehabilitation Science, Daegu University, Daegu, Republic of Korea

Objective: The purpose of this study was to evaluate the relationship between quality of life (QoL) of the caregiver and disease severity with motor function in children with cerebral palsy (CP).

Design: Cross-sectional study.

Methods: Research data were collected in the Rehabilitation Clinic of Daegu University. The Gross Motor Function Measure (GMFM-88) and the functional independence measure (FIM) were used for assessment by three occupational therapists, and the 36-item short form health survey (SF-36) were applied to the caregivers. One hundred six caregivers of under 18 years who were diagnosed with CP completed a survey and interview. The caregivers' QoL was evaluated using Medical Outcomes Study SF-36. The children's motor function was scored using GMFM-88 in five dimensions: lying and rolling; sitting; crawling and kneeling; standing and walking, running and jumping and CP's FIM scores.

Results: Out of the 8 domains of the Medical Outcomes Study SF-36, the "physical functioning", "physical role functioning", "mental health", and "bodily pain" domains were significantly correlated to "total" percentage scores of the GMFM-88 ( $p<0.05)$. In addition, the "mental health" domain was correlated to each subdomain of the GMFM-88, which includes, "lying and rolling", and "crawling and kneeling". Similarly, of Medical Outcomes Study SF-36, "physical functioning", "bodily pain", and "mental health" domains were significantly correlated with "transfer" and "locomotion" of FIM scores $(p<0.05)$.

Conclusions: This study showed that the QoL of the caregivers were well correlated with the motor function of children with CP. It is also important to support not only physical health but also psychological health of caregivers of children with $\mathrm{CP}$, especially those with severe motor function.

Key Words: Caregivers, Cerebral palsy, Quality of life

\section{Introduction}

Cerebral palsy (CP) is a complex clinical term for a condition that arises in early stage of brain development, described as a set of conditions associated with major physical impairment, a range of severity levels, and other developmental deficits [1]. Considering its clinical complexity, this notion was suggested for defining $\mathrm{CP}$ : “ $\mathrm{CP}$ describes a group of permanent disorders of the development of movement and posture, causing activity limitation, that are attributed to non-progressive disturbances that occurred in the de- veloping fetal or infant brain. The motor disorders of CP are often accompanied by disturbances of sensation, perception, cognition, communication, and behavior, by epilepsy, and by secondary musculoskeletal problems [2]."

Children with CP often have chronic non-progressive neurological deficits; therefore, rearing a child with impairment often has a detrimental effect on caregivers' lives because children with $\mathrm{CP}$ require continuous intensive treatment and care from caregivers. Experiencing such an environment makes caregivers stressed and depressed in the long term, due to both physical response stresses such as physical

Received: 2 February, 2017 Revised: 13 February, 2017 Accepted: 24 February, 2017

Corresponding author: Chang-Kyo Yun

Department of Physical Therapy, Rehabilitation Clinic of Daegu University, 201 Daegudae-ro, Naeri-ri, Jillyang-eup, Gyeongsan 38453, Republic of Korea Tel: 82-53-650-8090 Fax: 82-53-650-8089 E-mail: puhaha1116@naver.com

(c) This is an Open-Access article distributed under the terms of the Creative Commons Attribution Non-Commercial License (http://creativecommons.org/licens es/by-nc/4.0) which permits unrestricted non-commercial use, distribution, and reproduction in any medium, provided the original work is properly cited.

Copyright $@ 2017$ Korean Academy of Physical Therapy Rehabilitation Science 
fatigue and musculoskeletal pain, and emotional response stresses including nervousness, anxiety, distress, and grief [3-6]. Caring for a family member with a chronic disease can result in feelings of overload or tension and can even reduce caregivers' quality of life (QoL) [7-9].

There is a noticeable lack of research on the QoL for caregivers of children with CP. Caregiver's QoL has been commonly measured using the Medical Outcomes Study 36-item short form health survey (SF-36), which reflects both physical stress and emotional state [8,10-12]. However, those previous studies only analyzed the caregivers' demographic data such as family income or children's disease severity such as Gross Motor Function Classification Scale (GMFCS) results, which classify the findings into five motor commitment levels [11,12].

Recently, in aspects of the biomedical health model that reflect a new general and holistic medical paradigm, detailed comprehension is needed to understand the biopsychosocial aspects of caregivers of children with CP to thus understand how neurologic deficits can affect caregivers' and families' lives. Therefore, medical professionals including physiatrists, physical therapists, and occupational therapists have to consider both the children's physical improvement and the entire family's environment, primarily the caregivers' QoL.

The aim of our study was to evaluate the relationships between QoL in the caregivers of children with CP, and the children's detailed disease severity, especially with regard to motor function.

\section{Methods}

\section{Subjects}

This study was cross-sectional and descriptive. We included 106 caregivers of children aged under 18 years who were diagnosed with CP (both male and female) and were undergoing rehabilitation therapy, including physiotherapy, occupational therapy, and functional electrical stimulation in the Rehabilitation Clinic of Daegu University.

\section{Instrument}

We used the Gross Motor Function Measure-88 (GMFM-88) and functional independence measure (FIM) for assessing motor commitment level of children with CP. To analyze the QoL of caregivers of children with CP, the Medical Outcomes Study SF-36 questionnaire was used.

The GMFM-88 is an assessment tool designed to measure and record movement levels according to time flow and results. And has been widely used for clinical measurements to assess the gross motor function of $\mathrm{CP}$ and Down syndrome. The GMFM- 88 has shown proven reliability. This instrument assesses the motor function in five dimensions: lying and rolling; sitting; crawling and kneeling; standing and walking, running and jumping [13].

The FIM, a system for measurement of disability based on the International Classification of Impairment, Disabilities and Handicaps, measures level of a patient's disability and provides how much assistance is needed for the individual to implement the activities of daily living. This instrument contains 18 items including 13 motor tasks in four domains: (1) self-care domain (eating, grooming, bathing, upper and lower body dressing, toileting); (2) sphincter control domain (bladder and bowel management); (3) transfer domain (bed/chair/wheelchair, toilet, tub/shower); and (4) locomotion domain (walk/wheelchair, stairs) and five cognitive tasks in two domains: (1) communication domain (comprehension, expression); and (2) social cognition domain (social interaction, problem solving, memory). The 'motor subtotal' scores mean summation of the scores including 'self-care', 'sphincter control', 'transfer', and 'locomotion' domains. And the 'cognitive subtotal' scores include 'communication' and 'social cognition' domains. Each tasks are scored in 7-point ordinal scale that means from total assistance to complete independence [14].

The SF-36 has been most widely used generic QoL assessment questionnaires. Reliability coefficient Cronbach's $\alpha$ was 0.93 , the relative validity coefficient of the physical factor was 0.79 and Mental component was 1.02 [15]. It has been used for non-specific age, disease, or intervention group, and allows comparisons between different diseases and intervention [16]. It comprises 36 items and is classified into 8 domains - (1) functional activity (10 items); (2) physical conditions (4 items); (3) pain (2 items); (4) general health status (5 items); (5) vitality (4 items); (6) social conditions ( 2 items); (7) emotional conditions (3 items); and (8) mental health (5 items). And using the SF-36, the previous studies could assess both negative (disease or illness) and positive (well-being) health aspects and this questionnaire also reflects both physical stress and emotional distress $[11,12]$. The SF-36 scores range from 0 to 100 , meaning score 0 to the worst and 100 to the best health status.

\section{Procedures}

The caregivers were provided written informed consent 
Table 1. General characteristics of children with $\mathrm{CP}(\mathrm{N}=106)$

\begin{tabular}{lc}
\hline Characteristic & Frequency $(\%)$ \\
\hline Age (y) & $13.7(3.5)$ \\
Gender (male/female) & $62(58.5) / 44(41.5)$ \\
CP type & $88(83.0)$ \\
Spastic & $15(14.2)$ \\
Athetoid & $3(2.8)$ \\
Ataxic & $0(0)$ \\
Hypotonic & $0(0)$ \\
Mixed & \\
Tone distribution & $14(13.2)$ \\
Hemiplegic & $36(34.0)$ \\
Diplegic & $52(49.1)$ \\
Quadriplegic & $4(3.8)$ \\
Other & \\
GMFCS & $17(16.0)$ \\
Level I & $13(12.3)$ \\
Level II & $16(15.1)$ \\
Level III & $33(31.1)$ \\
Level IV & $27(25.5)$ \\
Level V & \\
Schooling & $24(22.6)$ \\
No school & $82(77.4)$ \\
School & $96(90.6)$ \\
Complication & $10(9.4)$ \\
None & $0(0)$ \\
1 &
\end{tabular}

Values are presented as mean (SD) or $\mathrm{n}(\%)$.

The sum of the percentages does not equal $100 \%$ because of rounding.

CP: cerebral palsy, GMFCS: Gross Motor Function Classification Scale.

Table 2. General characteristics of caregivers and family

$(\mathrm{N}=106)$

\begin{tabular}{lc}
\hline \multicolumn{1}{c}{ Characteristic } & Frequency (\%) \\
\hline Age (y) & $48.5(6.4)$ \\
Relationship with child & $60(56.6)$ \\
Mother & $44(41.5)$ \\
Father & $2(1.9)$ \\
Others & \\
Marital status & $98(92.5)$ \\
Married & $2(1.9)$ \\
Re-married & $3(2.8)$ \\
Divorced & $3(2.8)$ \\
Widow & \\
Educational status & $0(0)$ \\
Illiterate & $6(5.7)$ \\
Primary school & $5(4.7)$ \\
Secondary school & $30(28.3)$ \\
High school & $65(61.3)$ \\
University &
\end{tabular}

Table 2. Continued

\begin{tabular}{|c|c|}
\hline Characteristic & Frequency $(\%)$ \\
\hline \multicolumn{2}{|l|}{ Health status } \\
\hline Very not healthy & $2(1.9)$ \\
\hline Not healthy & $21(19.8)$ \\
\hline Healthy & $83(78.3)$ \\
\hline \multicolumn{2}{|l|}{ Employment } \\
\hline Employed & $68(64.2)$ \\
\hline Unemployed & $38(35.8)$ \\
\hline \multicolumn{2}{|l|}{ Spouse employment } \\
\hline Employed & $67(63.2)$ \\
\hline Unemployed & $39(36.8)$ \\
\hline \multicolumn{2}{|l|}{ Knowledge about CP } \\
\hline Poor & $11(10.4)$ \\
\hline Average & $70(66.0)$ \\
\hline Good & $25(23.6)$ \\
\hline \multicolumn{2}{|l|}{ Day spent with child (hr) } \\
\hline$<6$ & $39(36.8)$ \\
\hline $6-12$ & $39(36.8)$ \\
\hline $13-17$ & 0 \\
\hline$\geq 18$ & $28(26.4)$ \\
\hline \multicolumn{2}{|l|}{ Duration of care (y) } \\
\hline$<5$ & $4(3.8)$ \\
\hline $5-10$ & $9(8.5)$ \\
\hline$>10$ & $93(87.7)$ \\
\hline \multicolumn{2}{|l|}{ Having another child with CP } \\
\hline Yes & $16(15.1)$ \\
\hline No & $68(64.2)$ \\
\hline Don't have another child & $22(20.8)$ \\
\hline \multicolumn{2}{|l|}{ No of other children } \\
\hline None & $22(20.8)$ \\
\hline 1 & $60(56.6)$ \\
\hline Two and more & $24(22.6)$ \\
\hline \multicolumn{2}{|c|}{ Availability of health insurance } \\
\hline Available & $26(24.5)$ \\
\hline Not available & $80(75.5)$ \\
\hline \multicolumn{2}{|c|}{ Family income $(1,000,000 \mathrm{KRW})$} \\
\hline$<10$ & $13(12.3)$ \\
\hline $10-19.9$ & $28(26.4)$ \\
\hline $20-29.9$ & $16(15.1)$ \\
\hline $30-39.9$ & $22(20.8)$ \\
\hline$\geq 40$ & $27(25.5)$ \\
\hline \multicolumn{2}{|l|}{ Religion } \\
\hline Presence & $49(46.2)$ \\
\hline Absence & $57(53.8)$ \\
\hline
\end{tabular}

Values are presented as mean (SD) or $\mathrm{n}(\%)$.

The sum of the percentages does not equal $100 \%$ because of rounding.

CP: cerebral palsy, KRW: Korean won. 
prior to participation, agreed to participate in the survey after reading an informed consent about the survey for complying research ethics. The instruments such as GMFM-88, FIM and SF-36 were applied between November and December 2016. The GMFM-88 and FIM were practiced by 3 occupational therapists to children with CP, and the SF-36 and were applied to the caregivers by survey.

\section{Statistical analysis}

The IBM SPSS Statistics ver. 23.0 (IBM Co., Armonk, NY, USA) was used to analyze the data. To evaluate the correlation between QoL of caregivers and children's motor function, Pearson's correlation and analysis of variance were used. In all analyses, significance was set at 5\%.

\section{Results}

The general characteristics of both children and their caregivers have been documented (Tables 1,2). The chil- dren's age ranged from 5 to 18 years (average, 14 years). One hundred six children were included (male, 62; female, 44). In the aspect of clinical and anatomic classification, 14 children had spastic hemiplegia, 31 had spastic diplegia, 2 had ataxic diplegia, 33 had spastic quadriplegia, 14 had athetoid quadriplegia, and 12 had other spastic tone distributions. With regard to the GMFCS level, the 106 children were distributed as follows: 17 level I, 13 level II, 16 level III, 33 level IV, and 27 level V (Table 1). The caregiver's age ranged from 36 to 65 years (average, 48.5 years). Other general characteristics of the caregivers are described (Table 2). The other descriptive data of children's motor function and caregiver's QoL scores are shown (Table 3).

In motor function and QoL, among the eight domains of SF-36, the physical functioning $(\mathrm{r}=0.297)$, physical role functioning ( $\mathrm{r}=0.215)$, and bodily pain $(\mathrm{r}=-0.280)$ was correlated with the total percentage scores of GMFM-88. Moreover, the physical functioning was correlated to each subdomain of GMFM-88 including lying and rolling ( $\mathrm{r}=$

Table 3. Descriptive of children's motor function and caregivers' QoL

\begin{tabular}{|c|c|c|c|}
\hline Descriptive & Scale & Subscale & Mean (SD) \\
\hline \multirow[t]{17}{*}{ Children } & GMFM-88 (score) & Lying and rolling & $75.0(30.4)$ \\
\hline & & Sitting & $60.4(39.8)$ \\
\hline & & Crawling and kneeling & $48.7(38.6)$ \\
\hline & & Standing & $28.3(34.2)$ \\
\hline & & Walking, running and jumping & $24.1(32.0)$ \\
\hline & & Total & $18.7(31.0)$ \\
\hline & FIM (score) & Motor & \\
\hline & & Self care & $17.9(11.6)$ \\
\hline & & Sphincter control & $10.9(4.2)$ \\
\hline & & Transfer & $10.8(7.0)$ \\
\hline & & Locomotion & $6.2(4.3)$ \\
\hline & & Motor subtotal & $17.9(27.0)$ \\
\hline & & Cognitive & \\
\hline & & Communication & $9.2(4.2)$ \\
\hline & & Social cognition & $12.3(6.0)$ \\
\hline & & Cognitive subtotal & $8.4(12.2)$ \\
\hline & & Total & $26.8(38.6)$ \\
\hline \multirow[t]{9}{*}{ Caregiver } & SF-36 (score) & Social role functioning & $3.9(2.5)$ \\
\hline & & Physical functioning & $26.4(4.3)$ \\
\hline & & Physical role functioning & $6.8(1.5)$ \\
\hline & & Emotional role functioning & $5.2(1.2)$ \\
\hline & & General health perceptions & $18.1(3.1)$ \\
\hline & & Mental health & $20.4(3.4)$ \\
\hline & & Bodily pain & $3.8(1.7)$ \\
\hline & & Vitality & $16.3(4.8)$ \\
\hline & & Total & $58.9(73.0)$ \\
\hline
\end{tabular}

QoL: quality of life, GMFM-88: Gross Motor Function Measure-88, FIM: functional independence measure, SF-36: 36-item short form health survey. 
Table 4. Statistically significant correlations between children's motor function and caregivers' QoL (SF-36)

\begin{tabular}{lcccc}
\hline \multirow{2}{*}{ Scales } & \multicolumn{3}{c}{ SF-36 } \\
\cline { 2 - 5 } & Physical functioning & Physical role functioning & Mental health & Bodily pain \\
\hline GMFM-88 & & & & \\
Lying and rolling & $0.306(0.001)^{* *}$ & $0.143(0.142)$ & $0.213(0.028)^{*}$ & $-0.154(0.115)$ \\
$\quad$ Sitting & $0.349(0.000)^{* *}$ & $0.247(0.011)^{*}$ & $0.179(0.066)^{*}$ & $-0.316(0.001)^{* *}$ \\
Crawling and kneeling & $0.260(0.007)^{* *}$ & $0.200(0.039)^{*}$ & $0.202(0.037)^{*}$ & $-0.269(0.005)^{* *}$ \\
Standing & $0.214(0.028)^{*}$ & $0.192(0.049)^{*}$ & $0.132(0.177)$ & $-0.258(0.008)^{* *}$ \\
Walking, running, and jumping & $0.081(0.413)^{* *}$ & $0.169(0.086)$ & $0.081(0.413)$ & $-0.225(0.022)^{*}$ \\
Total & $0.297(0.002)^{* *}$ & $0.215(0.027)^{*}$ & $0.182(0.062)$ & $-0.280(0.004)^{* *}$ \\
FIM & & & & \\
Transfer & $0.245(0.011)^{*}$ & $0.188(0.054)$ & $0.253(0.009)^{* *}$ & $-0.249(0.010)^{*}$ \\
Locomotion & $0.260(0.007)^{* *}$ & $0.218(0.025)^{*}$ & $0.222(0.022)^{*}$ & $-0.220(0.023)^{*}$ \\
Motor subtotal & $0.235(0.015)^{*}$ & $0.146(0.136)$ & $0.198(0.042)^{*}$ & $-0.184(0.058)$ \\
\hline
\end{tabular}

QoL: quality of life, SF-36: 36-item short form health survey, GMFM-88: Gross Motor Function Measure-88, FIM: functional independence measure.

${ }^{*} p<0.05, \stackrel{* *}{p}<0.01$.

0.306), sitting $(\mathrm{r}=0.349)$, crawling and kneeling $(\mathrm{r}=0.260)$, and standing $(\mathrm{r}=0.214)$. The physical role functioning was correlated to sitting $(\mathrm{r}=0.247)$, crawling and kneeling $(\mathrm{r}=0.200)$, and standing $(\mathrm{r}=0.192)$. The mental health was correlated to lying and rolling $(\mathrm{r}=0.213)$ and crawling and kneeling ( $\mathrm{r}=0.202)$. The bodily pain was correlated to sitting $(\mathrm{r}=-0.316)$, crawling and kneeling $(\mathrm{r}=-0.269)$, standing $(\mathrm{r}=-0.258)$, and walking, running, and jumping $(\mathrm{r}=-0.280)$.

In the same manner, the physical functioning and mental health domains were correlated with transfer $(r=0.245$; $r=$ 0.253 ), locomotion $(r=0.260 ; r=0.222)$, and motor subtotal $(\mathrm{r}=0.235 ; \mathrm{r}=0.198)$ domains of the FIM scores. The physical role functioning domain was correlated with locomotion $(\mathrm{r}=0.218)$, and bodily pain domain was correlated with transfer $(\mathrm{r}=-0.249)$, and locomotion $(\mathrm{r}=-0.220)$ (Table 4).

In general characteristics and QoL, among the eight domains of SF-36, emotional role functioning ( $\mathrm{r}=0.012)$ domain was correlated to relationship with child as if others were different from mother and father. The general health $(\mathrm{r}=0.236)$ and mental health $(\mathrm{r}=0.252)$ were correlated to caregivers' age. The physical functioning $(\mathrm{r}=0.009)$ and general health $(r=0.019)$ domains were correlated to caregivers' health status. The physical functioning ( $\mathrm{r}=0.043$ ) and bodily pain $(\mathrm{r}=0.021)$ domains were correlated to duration of care. The physical role functioning $(\mathrm{r}=0.025)$ domain was correlated to the number of other children. Moreover, the religion affects the mental health $(r=0.032)$. The other general characteristics of caregivers not mentioned here did not correlate with QoL of caregivers.

\section{Discussion}

Our study investigated the relationship between QoL in the caregivers of children with $\mathrm{CP}$ and children's motor function. In literature, the caregivers of children with severe clinical impairments, especially with regard to motor function, are more likely to have greater physical and mental distress than other caregivers [17-21]. In addition, caregivers' QoL was significantly affected by the motor function of children with CP in this study. Interestingly, another significant association was found between caregivers' general characteristics and their QoL.

In many previous studies, caregivers of children with $\mathrm{CP}$ had poorer QoL compared to caregivers of healthy children [17,21-23]. Tuna et al. [23] evaluated the QoL of 40 primary caregivers of children with CP compared to 40 primary caregivers of children without CP. This study used both SF-36 and GMFCS questionnaires; the dispersion of GMFCS level of children with CP was non-homogeneous, with more children at levels 1 and 5. The scores for functional capacity, vitality, general health status, and emotional states were significantly lower and the pain domain was higher than in the primary caregivers of children with CP compared to the control group. The other Turkish study evaluated the QoL of 40 mothers of children with $\mathrm{CP}$, compared to 44 mothers of children with other problems such as general deconditioning, fever, or diarrhea using the SF-36 and GMFCS [21]. The overall scores of the SF-36 domains were significantly lower in mothers of children with CP than in the non-chroni- 
cally diseased group. Moreover, a recent study evaluated not only the QoL in caregivers of children with $\mathrm{CP}$ but also their emotional distress [12]. In the same axis, the other study showed that all the impaired domains of caregivers' QoL were well correlated with the depression index scores [18].

However, those previous studies had not evaluated the factors affecting QoL in detail. Basaran et al. [24] evaluated children's factors that could affect caregivers' QoL and emotional distress by researching the five-level GMFCS. Each participant's QoL and emotional distress were scored by the Turkish Form of World Health Organization Quality of Life Assessment (WHOQOL-BREF TR), beck depression index (BDI), and beck anxiety inventory [11,24,25]. In this study, the physical, psychological, and total scores of WHOQOL- BREF TR and BDI of the caregivers of children with $\mathrm{CP}$ were statistically significantly correlated with their wards' GMFCS scores. Contrary to this, other previous studies have shown no significant correlations among caregivers' QoL, emotional stress, and the children's GMFCS levels $[19,22]$. However, our study showed coincident results with Basaran et al. [24]. The more impaired the children's motor function, the worse the caregivers' QoL. In addition, unlike in previous studies, our study used more precise motor function scales such as GMFM-88 and FIM scores that included sub-domains that were more detailed than GMFCS score. Furthermore, our study evaluated QoL using SF-36, which could evaluate both caregivers' physical and mental distress. Interestingly, our study also identified that caregivers' general characteristics such as their relationship with the child, the caregivers' age, health status, religion, care duration, and the number of other children could also affect caregivers' QoL.

The limitations of the present study were as follows. We could investigate the correlation degree between children's motor function and QoL, but our study generally showed low-degree correlations. Moreover, its cross-sectional design meant that we could not conclude that children's motor function improvement would directly affect their caregivers' QoL. While conducting the present study, we perceived that there had been inadequate research into the leisure activities of such caregivers. Various studies of leisure activities, which may improve caregivers' QoL, must be conducted. In the future, research should include a control group who have children without $\mathrm{CP}$ and perform a prospective study that reflects the effect of motor function improvements of children with CP to caregivers' QoL and other such emotional distress [26].
In spite of these limitations, our study identified the need to pay attention to caregivers' physical and psychological distress. In comprehensive care paradigms, team-approached rehabilitation should not only be performed for children with CP but also for their caregivers. Thus, caregiver interventions including mental counseling and practical relaxation techniques by a professional medical team may allow both caregivers and the children with disabilities under their care to lead healthier lives [27-30].

Our study evaluated the relationship between QoL in caregivers of children with $\mathrm{CP}$ and the children's motor function. In conclusion, children's motor function affects caregivers' QoL in not only physical but also psychological sides. This is the point that to improve QoL and mental health in caregivers of children with $\mathrm{CP}$, more aggressive treatment such as physiotherapy and occupational therapy should be conducted to improve children's motor function and associated sequelae. In addition, for the perspective on the comprehensive care, premeditated intervention needs to be performed to the environments of both patients and caregivers.

\section{Conflict of Interest}

The authors declared no potential conflicts of interest with respect to the authorship and/or publication of this article.

\section{References}

1. Bax MC, Flodmark O, Tydeman C. Definition and classification of cerebral palsy. From syndrome toward disease. Dev Med Child Neurol Suppl 2007;109:39-41.

2. Rosenbaum P, Paneth N, Leviton A, Goldstein M, Bax M, Damiano D, et al. A report: the definition and classification of cerebral palsy April 2006. Dev Med Child Neurol Suppl 2007; 109:8-14.

3. Ko JY, Lee SM. Funtions (mobility, self-care, social ability) and health-related quality of life in children with cerebral palsy. J Korean Soc Phys Ther 2010;22:37-44.

4. Hastings RP. Child behaviour problems and partner mental health as correlates of stress in mothers and fathers of children with autism. J Intellect Disabil Res 2003;47:231-7.

5. Breslau N, Staruch KS, Mortimer EA Jr. Psychological distress in mothers of disabled children. Am J Dis Child 1982;136:682-6.

6. Shim YW. Intervention methods and comparison analysis of stress for mothers with cerebral palsy. Korean J Phys Mult Health Disabil 1995;25:67-87.

7. Carr AJ, Thompson PW, Kirwan JR. Quality of life measures. Br J Rheumatol 1996;35:275-81.

8. Felce D, Perry J. Quality of life: its definition and measurement. 
Res Dev Disabil 1995;16:51-74.

9. Sales E. Family burden and quality of life. Qual Life Res 2003;12 Suppl 1:33-41.

10. Ström H, Kreuter M, Rosberg S. Quality of life in parents/caretakers of children with cerebral palsy in Kampong Cham, Cambodia. J Trop Pediatr 2012;58:303-6.

11. Prudente CO, Barbosa MA, Porto CC. Relation between quality of life of mothers of children with cerebral palsy and the children's motor functioning, after ten months of rehabilitation. Rev Lat Am Enfermagem 2010;18:149-55.

12. Zanon MA, Batista NA. Quality of life and level of anxiety and depression in caregivers of children with cerebral palsy. Rev Paul Pediatr 2012;30:392-6.

13. Russell DJ, Rosenbaum PL, Cadman DT, Gowland C, Hardy S, Jarvis S. The gross motor function measure: a means to evaluate the effects of physical therapy. Dev Med Child Neurol 1989;31:341-52.

14. Dodds TA, Martin DP, Stolov WC, Deyo RA. A validation of the functional independence measurement and its performance among rehabilitation inpatients. Arch Phys Med Rehabil 1993; 74:531-6.

15. Ware JE Jr, Kosinski M, Bayliss MS, McHorney CA, Rogers WH, Raczek A. Comparison of methods for the scoring and statistical analysis of SF-36 health profile and summary measures: summary of results from the medical outcomes study. Med Care 1995;33(4 Suppl):AS264-79.

16. Ciconelli RM, Ferraz, MB, Santos W, Meinão I, Quaresma MR. Tradução para a língua portuguesa e validação do questionário genérico de avaliação de qualidade de vida SF-36 (Brasil SF-36). Rev Bras Reumatol 1999;39:143-50.

17. Altindag Ö, Işcan A, Akcan S, Koksal S, Erçin M, Ege L, et al. Anxiety and depression levels in mothers of children with cerebral palsy. Turk J Phys Med Rehab 2007;53:22.

18. Ones K, Yilmaz E, Cetinkaya B, Caglar N. Assessment of the quality of life of mothers of children with cerebral palsy (primary caregivers). Neurorehabil Neural Repair 2005;19:232-7.

19. Cheshire A, Barlow JH, Powell LA. The psychosocial well-be- ing of parents of children with cerebral palsy: a comparison study. Disabil Rehabil 2010;32:1673-7.

20. Eker L, Tüzün EH. An evaluation of quality of life of mothers of children with cerebral palsy. Disabil Rehabil 2004;26:1354-9.

21. Kaya K, Unsal-Delialioglu S, Ordu-Gokkaya NK, Ozisler Z, Ergun N, Ozel S, et al. Musculo-skeletal pain, quality of life and depression in mothers of children with cerebral palsy. Disabil Rehabil 2010;32:1666-72.

22. Raina P, O’Donnell M, Rosenbaum P, Brehaut J, Walter SD, Russell D, et al. The health and well-being of caregivers of children with cerebral palsy. Pediatrics 2005;115:e626-36.

23. Tuna H, Unalan H, Tuna F, Kokino S. Quality of life of primary caregivers of children with cerebral palsy: a controlled study with short form-36 questionnaire. Dev Med Child Neurol 2004;46:647-8.

24. Basaran A, Karadavut KI, Uneri SO, Balbaloglu O, Atasoy N. The effect of having a children with cerebral palsy on quality of life, burn-out, depression and anxiety scores: a comparative study. Eur J Phys Rehabil Med 2013;49:815-22.

25. Unsal-Delialioglu S, Kaya K, Ozel S, Gorgulu G. Depression in mothers of children with cerebral palsy and related factors in Turkey: a controlled study. Int J Rehabil Res 2009;32:199-204.

26. Jeong YG, Jeong YJ, Bang JA. Effect of social support on parenting stress of korean mothers of children with cerebral palsy. J Phys Ther Sci 2013;25:1339-42.

27. Hernandez NE, Kolb S. Effects of relaxation on anxiety in primary caregivers of chronically ill children. Pediatr Nurs 1998; 24:51-6.

28. Rone-Adams SA, Stern DF, Walker V. Stress and compliance with a home exercise program among caregivers of children with disabilities. Pediatr Phys Ther 2004;16:140-8.

29. Lee NJ, Oh TY. The effect of motor ability in children with cerebral palsy on mastery motivation. J Korean Soc Phys Ther 2014; 26:315-23.

30. Kwon MJ. Satisfaction of utilization of physical therapy and quality of life for caregivers of cerebral palsy children. J Korean Soc Phys Ther 2009;21:55-63. 